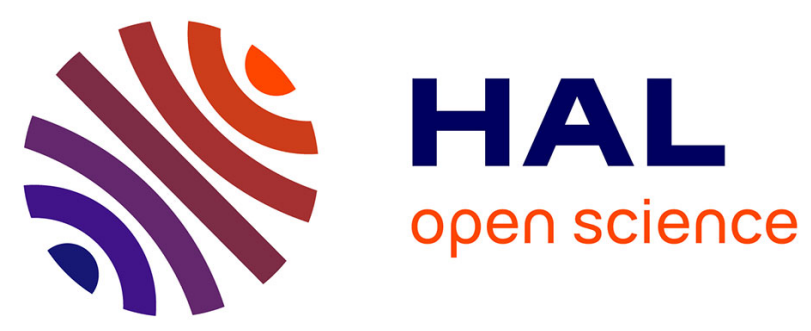

\title{
Modelling of anisotropic cortical bone based on degradation mechanism
}

\author{
C. Cluzel, R. Allena
}

\section{To cite this version:}

C. Cluzel, R. Allena. Modelling of anisotropic cortical bone based on degradation mechanism. Computer Methods in Biomechanics and Biomedical Engineering, 2015, 18 (sup1), pp.1914-1915. 10.1080/10255842.2015.1070580 . hal-01894712

\section{HAL Id: hal-01894712 \\ https://hal.science/hal-01894712}

Submitted on 11 May 2020

HAL is a multi-disciplinary open access archive for the deposit and dissemination of scientific research documents, whether they are published or not. The documents may come from teaching and research institutions in France or abroad, or from public or private research centers.
L'archive ouverte pluridisciplinaire HAL, est destinée au dépôt et à la diffusion de documents scientifiques de niveau recherche, publiés ou non, émanant des établissements d'enseignement et de recherche français ou étrangers, des laboratoires publics ou privés. 


\title{
Modelling of anisotropic cortical bone based on degradation mechanisms
}

\author{
C. Cluzela and R. Allena ${ }^{b}$ \\ aLMT-Cachan/ENS-Cachan/CNRS/Université Paris Saclay, Cachan, France; ${ }^{b}$ Arts et Metiers ParisTech, LBM, Paris, France
}

KEYWORDS Femoral diaphysis; personalized geometry; microstructure; anisotropy; damage

\section{Introduction}

When an orthopaedic prosthesis is implanted, it is essential to ensure bone remodelling and to maintain the proper mechanical properties under specific loading conditions. The coupling between the remodelling and the loading is ensured by the mechanical stress inducing the osteogenesis around the implant (Frost 2003). The objective of the present work is to develop a finite element tool and a multiscale mechanical model of the behaviour of the cortical bone in order to be able to optimize the stiffness of the prosthetic implant and to avoid overloaded or underloaded regions.

\section{Methods}

The patient specific geometry (external and internal cortical surfaces) of a femoral diaphysis is generated using the three-dimensional (3D) segmentation of the specimen from the CT scan data and a specific personalization method (Duchemin, Mitton, et al. 2008).

Cortical bone is constituted by an inner network of tubular osteons, oriented along the main axis of the bone, surrounded by a thin layer of peripheral lamellae (Currey 2002). Here, we consider both the core of the cortical bone, which is modelled as a volume and described as an elastic isotropic transverse material, and the peripheral circumferential lamellae, which are represented by a shell surface with an elastic isotropic behaviour.

Given the irregular shape of the diaphysis, one issue consists of defining the principal axes of anisotropy. To do so, we employ a computational approach allowing to determine a specific curvilinear system of coordinates and to compute each of them using the relationship between the solution of the Laplace's equation on a given domain with appropriate boundary conditions and the proper geometry of the same domain (Allena \& Aubry 2011).
Let $\Omega$ be the cortical bone domain, and $\partial \Omega_{e}$ and $\partial \Omega_{i}$ be the external and internal surfaces, respectively, then we define the electric potential $V$ within the thickness $h$ through the Laplace's equation and the Dirichlet's boundary conditions as follows:

$$
\left\{\begin{array}{l}
-\operatorname{div}(c \nabla V)=0 \text { inside } \Omega \\
V=+\frac{h}{2} \text { on the external boundary } \partial \Omega_{e} \\
V=-\frac{h}{2} \text { on the external boundary } \partial \Omega_{i} \\
\frac{\partial V}{\partial n}=0 \text { on the top and bottem boundaries }
\end{array}\right.
$$

where $n$ is the geometrical outward normal vector and the coefficient $c$ is a scalar assuming that the osteons are mostly oriented alongside the local tangent surface. Then, an approximated normal vector to the middle surface of the cortical bone can be computed (Figure 1(a)). Similarly, we compute the vector following the longitudinal curvature of the cortical domain of the diaphysis and, by a set of crossed products, the full 3D orthonormal basis can be deduced (Figure 1(b) and (c)).

The mechanical parameters of the model are taken from (Bernard et al. 2013) and we assume that the elastic compliance tensor is homogeneously affected over time. Additionally, although a mineralization indicator is necessary in order to adjust the parameters of the compliance tensor according to the in vivo data (Duchemin, Bousson, et al. 2008), an elastic shear-based fitting is used.

The damaging is gradually triggered by the microfractures at the osteons interfaces (Vashishth 2007; Ascenzi et al. 2013). Its ductile modelling is associated to the evolution of the shear modulus and is induced by the shear stress in the local framework.

In this specific case, a set of torsion tests is used to obtain the evolution law of the damage. Additionally, a brittle criterion is employed to describe the osteons 


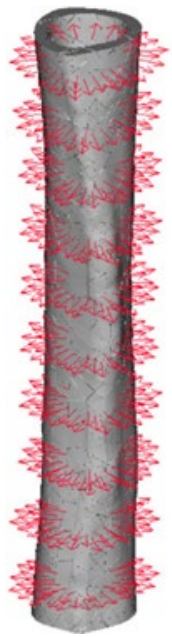

(a)

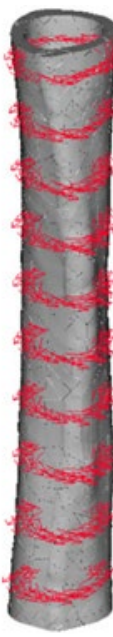

(b)

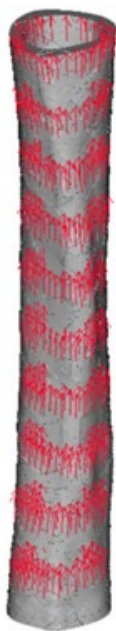

(c)
Figure 1. Curvilinear system of coordinates computed for the femoral diaphysis: (a) the radial, (b) the circumferential and (c) the longitudinal unit vectors.

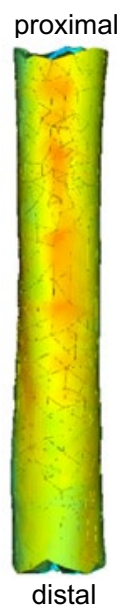

(a)

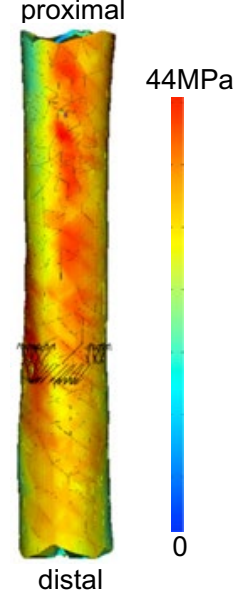

(b)

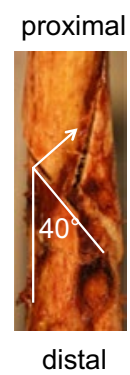

(c)
Figure 2. (a) Shear stress; (b) first principal stress and direction (black arrows); (c) experimental crack and direction.

fracture along their main directions. Such criterion is often identified through a classical traction test (Reilly \& Burstein 1975). However, we have recently proposed the Brazilian test as a consistent alternative to account for the anisotropic brittle behaviour (Allena \& Cluzel 2014).

Finally, a brittle Rankine criterion is adopted to evaluate its failure mechanism, whose identification is acquired through the failure during the torsion tests.

\section{Results and discussion}

Here, we present some preliminary results of an elastic finite element simulation of a diaphysis submitted to pure torsion. The shear stress is homogenously distributed within the diaphysis (Figure 2(a)) and in the same order of magnitude as the main principal stress (Figure 2(b)). Additionally, the associated principal direction (black arrows in Figure 2(b)) is perpendicular to the failure plan and is in agreement with the experimental crack orientation (Figure 2(c)). Such results show that the mechanism triggering the fracture is correctly taken into account by the brittle criterion implemented in the finite element model.

\section{Acknowledgments}

The authors are grateful to Pr Patricia Thoreux, Pr Wafa Skalli and Dr. Laura Li for their experimental work whose data have been exploited here.

\section{References}

Allena R, Aubry D. 2011. A novel technique to parametrize shell-like deformations inside biological membranes. Comput Mech. 47:409-423.

Allena R, Cluzel C. 2014. Identification of anisotropic tensile strength of cortical bone using Brazilian test. J Mech Behav Biomed Mater. 38:134-142.

Ascenzi M-G, Kawas NP, Lutz A, Kardas D, Nackenhorst U, Keyak JH. 2013. Individual-specific multi-scale finite element simulation of cortical bone of human proximal femur. J Comput Phys. 244:298-311.

Bernard S, Grimal Q, Laugier P. 2013. Accurate measurement of cortical bone elasticity tensor with resonant ultrasound spectroscopy. J Mech Behav Biomed Mater. 18:12-19.

Currey JD. 2002. Bones: structure and mechanics. [place unknown]: Princeton University Press.

Duchemin L, Bousson V, Raossanaly C, Bergot C, Laredo JD, Skalli W, Mitton D. 2008. Prediction of mechanical properties of cortical bone by quantitative computed tomography. Med Eng Phys. 30:321-328.

Duchemin L, Mitton D, Jolivet E, Bousson V, Laredo JD, Skalli W. 2008. An anatomical subject-specific FE-model for hip fracture load prediction. Comput Methods Biomech Biomed Engin. 11:105-111.

Frost HM. 2003. Bone's mechanostat: a 2003 update. Anat Rec A Discov Mol Cell Evol Biol. 275A:1081-1101.

Reilly DT, Burstein AH. 1975. The elastic and ultimate properties of compact bone tissue. J Biomech. 8:393-405.

Vashishth D. 2007. Hierarchy of bone microdamage at multiple length scales. Int J Fatigue. 29:1024-1033. 